\title{
External knot size and frequency in black spruce trees from an initial spacing trial in Thunder Bay, Ontario
}

\author{
Jeffrey G. Benjamin ${ }^{1,2}$, John A. Kershaw, Jr. ${ }^{3}$, Aaron R. Weiskittel ${ }^{1}$, Ying Hei Chuii ${ }^{3}$ and S.Y. Zhang ${ }^{4}$
}

\begin{abstract}
As growing space available for a given tree increases, crown size increases and branch size (and thus knot size) is generally greater. Increased tree spacing may also result in a higher knot frequency. Using a combination of nonlinear, multilevel mixed effects and generalized nonlinear modeling techniques, a series of equations were developed to predict size and number of knots with respect to vertical location in black spruce (Picea mariana [Mill.] BSP) trees from one of the oldest initial spacing trial in Thunder Bay, Ontario. The models developed in this paper focus only on live whorls and are intended to be linked with a growth and yield model. The maximum knot size model accounted for $74 \%$ of the total variation and had a root MSE of 2.03. Random effects terms accounted for an additional 3\% of the total variation. The relative knot size model accounted for $32 \%$ of the total variation and no significant random effects were found. The knot frequency model accounted for $45 \%$ of the total variation and the root MSE was 2.11 and no significant autocorrelation or random effects were observed. The results of this study indicated that black spruce knot properties were relatively insensitive to tree spacing given that they were largely accounted for by bole and crown size covariates.
\end{abstract}

Key words: maximum knot size, relative knot size, number of knots per whorl, plantation black spruce, nonlinear regression, nonlinear mixed effects

\section{RÉSUMÉ}

À mesure que l'espace disponible pour la croissance d'un arbre donné augmente, la taille de la cime saccroit et la taille des branches (et de ce fait la grosseur des nœuds) est généralement plus importante. Laugmentation de l'espacement entre les arbres peut également entraîner une plus grande fréquence de nœuds. Au moyen d'une combinaison d’effets non linéaires, à différents niveaux et mixtes ainsi que de techniques généralisées de modélisation non linéaire, une série déquations a été élaborée pour prédire la grosseur et le nombre de nouds se rapportant à leur emplacement vertical sur des épinettes noires (Picea mariana [Mill.] BSP) de l'un des tout premiers essais de dégagement initial réalisé à Thunder Bay en Ontario. Les modèles présentés dans cet article portent seulement sur les verticilles vivants et sont conçus pour être incorporés à un modèle de croissance et de rendement. Le modèle de grosseur maximale des nœuds a enregistré $74 \%$ de la variation totale et comportait une erreur quadratique moyenne de 2,03. Les effets imprévisibles comptaient pour un autre $3 \%$ de la variation totale. Le modèle de la grosseur relative des nœuds enregistrait $32 \%$ de la variation totale et aucun effet imprévisible n’a été détecté. Le modèle de fréquence des nœuds a enregistré $45 \%$ de la variation totale tout en ayant une erreur quadratique moyenne de 2,11 sans aucune auto-corrélation significative ou d'erreur imprévisible. Les résultats de cette étude indiquent que les caractéristiques des nœuds d'épinette noire sont relativement peu influencées par l'espacement entre les arbres étant donné quelles sont principalement dépendantes des covariables de la tige et de la taille de la cime.

Mots clés : grosseur maximale des nœuds, grosseur relative des nœuds, nombre de nœuds par verticille, plantation dépinette noire, régression non-linéaire, effets non-linéaires mixtes

\section{Introduction}

Black spruce (Picea mariana [Mill.] BSP) is one of the most important commercial species in Canada, with wood properties desired for both pulp and structural lumber applications. Cost-efficient management and value-added utilization of this resource is without question critical to each company's financial success. Forest managers have many options available to influence growth of black spruce stands such as silviculture and tree improvement, but arguably stand density management (e.g., initial spacing, thinning) or tree spacing at planting stage has the most important impact on tree growth and stand yield. A given area may be planted with seedlings from improved genetic stock or it may be allowed to regenerate naturally, but at some point in time a decision must be made with respect to growing space available for each tree. Many studies have shown that, for a given species, branch size (and thus knot size) generally increases with increasing tree spacing (Eversole 1955, Grah 1961, Bendtsen 1978, Ballard and Long 1988, Maguire et al. 1991, Haygreen and Bowyer 1996, Oliver and Larson 1996, MacDonald and Hubert 2002).

\footnotetext{
${ }^{1}$ School of Forest Resources, University of Maine, 5755 Nutting Hall, Orono, ME 04469, USA.

${ }^{2}$ Corresponding author. E-mail: Jeffrey.G.Benjamin@maine.edu

${ }^{3}$ Faculty of Forestry and Environmental Management, University of New Brunswick, P.O. Box 44555, 28 Dineen Drive, Fredericton, New Brunswick E3B 6C2.

${ }^{4}$ FPInnovations - Forintek Division, 2665 East Mall, Vancouver, British Columbia V6T 1W5.
} 
The obvious implication is that, as growing space available for a given tree increases, crown size increases. This increase in growth space may also result in larger knots and an increased knot frequency.

Over the past 30 years, numerous studies have examined branch characteristics such as size and vertical distribution (Drolet et al. 1971, Colin and Houllier 1991, Maguire et al. 1991, Doruska and Burkhart 1994, Maguire et al. 1994, Björklund and Petersson 1999, Maguire et al. 1999, Moberg 2000, Lemieux et al. 2001, Moberg 2001, Mäkinen and Mäkelä 2003, Lejeune 2004, Weiskittel et al. 2007a, Kershaw et al. 2009), leaf area (Gillespie et al. 1994, Kershaw and Maguire 1996, Maguire and Bennett 1996, Garber and Maguire 2005a), mortality (Kershaw et al. 1990, Fujimori 1993, Weiskittel et al. 2007b), structure (Cochrane and Ford 1978, Caron 1987) and frequency (Drolet et al. 1971, Doruska and Burkhart 1994, Maguire et al. 1994, Moberg 2000). With respect to the above studies, the only work related to black spruce is that of Drolet et al. (1971), Caron (1987), Lemieux et al. (2001), Lejeune (2004), and Kershaw et al. (2009).

Conifer tree branches inherently have multiple levels of nesting including individual whorl, tree, and stand-levels, so modelling branch characteristics is inherently complex. Kershaw et al. (2009) compared nonlinear mixed effects (nlme) and generalized nonlinear (gnls) techniques to develop a maximum knot size model for black spruce. They found that while inclusion of random effects was useful for addressing both within- and between-tree variation, its effectiveness was significantly reduced with improved model forms. In the final model form, the use of a mixed model approach only reduced root mean square error by $6 \%$ in comparison to the generalized nonlinear model. The objective of this paper is to develop a series of models to predict size and number of knots with respect to vertical location in black spruce trees and quantify their variation due to initial spacing. More specifically, this paper presents a series of models that predict: 1) maximum live whorl knot size, 2) relative knot size within each live whorl, and 3) number of live knots per whorl.

\section{Methods \\ Study sites}

The Ontario Ministry of Natural Resources (OMNR) established 2 initial spacing trials near Thunder Bay in 1950. Each trial contained white spruce (Picea glauca [Moench] Voss) and red pine (Pinus resinosa Ait.) in addition to black spruce. The sites are known as the Thunder Bay and Stanley Initial Spacing Trials. These are some of the oldest black spruce spacing trials in Canada. The objective of the trials was to determine effect of initial spacing on tree growth (height, diameter, and volume) and stand yield over time (Kerrio 1989). Blocks were established at spacings of $1.8 \mathrm{~m}, 2.7 \mathrm{~m}$ and $3.6 \mathrm{~m}$ for all species.

There were several problems with the Stanley Trial since establishment. Due to lack of stand tending, the $3.6-\mathrm{m}$ spaced blocks have completely failed. The surviving trees are essentially open-grown with crowns extending to within $0.5 \mathrm{~m}$ from the ground. Portions of the 1.8-m spaced blocks were affected by flooding resulting from uncontrolled beaver (Castor canadensis) activity in the northern section of the trial. Because of these problems, OMNR has permitted destructive sampling of trees within the Stanley trial for wood quality and product recovery research by FPInnovations - Forintek Division (Zhang et al. (2002).

In the spring of 2003, 18 trees were selected for this study. Initial spacing and stem form were the main tree selection criteria. Because of the problems listed above, none of the 18 trees selected for this study maintained their initial spacing. However, historical records provided by OMNR showed that all selected trees developed at their initial spacing until at least 1993 and more than half until 1998. Trees with forks or severely crooked stems visible from the ground were not included. A description of selected trees is shown in Table 1.

\section{Data collection}

Tree level and branch level data were collected on site. Prior to harvest, diameter at breast height, $\mathrm{DBH}$, (1.3 $\mathrm{m}$ above ground) was identified and measured to the nearest $0.1 \mathrm{~cm}$ on each tree. A line was painted on each tree from breast height to the ground indicating the north (orange) and south (blue) facing sides. Crown width, CRWIDTH, was calculated as the arithmetic average between crown width measurements in 2 directions (N-S and E-W). Once trees were felled, total height, TOTHT, height to base of crown, HTBC (lowest whorl with at least 3 live branches), and height to lowest live branch, HLLB, were measured. Branches were pruned with loppers leaving $5-\mathrm{cm}$ to $10-\mathrm{cm}$ stubs and the branch was identified as either live or dead. Depending on which side the tree fell, the north or south line was continued along the length of each stem. Trees were bucked into approximately $2.5-\mathrm{m}$ sections to facilitate measurement of external knot (i.e., branch stub) characteristics.

Distance to each knot from base of log was measured to the nearest $1 \mathrm{~cm}$ and used to calculate knot height, KNOTHT. Vertical knot diameter, VKD, was measured parallel to the stem and horizontal knot diameter, HKD, was measured perpendicular to VKD using a digital micrometer to the nearest $0.1 \mathrm{~mm}$. Knot size (basal branch diameter), KNOTD, was calculated as the arithmetic average of VKD and HKD. All knots (live or dead) were measured to a minimum size of $1.5 \mathrm{~mm}$; however, only live branches larger than $5.0 \mathrm{~mm}$ were used in the models developed in this paper (4615 knots $\geq 5.0 \mathrm{~mm}$, KNOTD between $5.0 \mathrm{~mm}$ and 43.0 $\mathrm{mm}$ with a mean of $11.0 \mathrm{~mm}$ and a standard deviation of 5.6 $\mathrm{mm}$ ). Once all field measurements were completed, data were entered into an Access database (Microsoft Corp., Redmond, WA) and imported into the R statistical software program ( $\mathrm{R}$ Development Core Team 2008).

Whorl locations (annual height increments) were not recorded in the field and were interpolated from branch
Table 1. Mean tree size and standard deviation (in parentheses) by initial spacing for destructively sampled black spruce trees at the Stanley Spacing Trial, near Thunder Bay, Ontario

\begin{tabular}{cccccc}
\hline $\begin{array}{c}\text { Initial } \\
\text { spacing }(\mathbf{m})\end{array}$ & $\begin{array}{c}\text { Sample } \\
\text { size }\end{array}$ & $\begin{array}{c}\text { DBH } \\
(\mathbf{c m})\end{array}$ & $\begin{array}{c}\text { Total height } \\
(\mathbf{m})\end{array}$ & Width $(\mathbf{m})$ & Length $(\mathbf{m})$ \\
\hline 1.8 & 8 & $17.1(2.2)$ & $16.8(1.0)$ & $1.5(0.5)$ & $5.4(1.1)$ \\
2.7 & 7 & $22.6(1.5)$ & $19.0(0.7)$ & $3.1(0.4)$ & $9.2(1.4)$ \\
3.6 & 3 & $25.5(3.7)$ & $16.7(0.2)$ & $4.7(1.0)$ & $14.5(0.3)$ \\
\hline
\end{tabular}


diameter measurements. The largest branches within each whorl are located at the top of each annual increment in black spruce (Caron 1987). Each whorl was located by plotting knot size, KNOTD, versus knot height, KNOTHT. The pattern of each whorl described above was used to locate the top of each whorl (WLTOP) as defined by location of the largest branches. The bottom of each whorl (WLBOT) was defined as the top of the next lower whorl. The visual whorl location methodology was verified using stem analysis data from the stump and the top of each $2.5 \mathrm{~m}$ section. Differences in age were compared to number of whorls identified. A complete description of the whorl location technique and other data collection techniques is found in Benjamin (2006).

\section{Model development}

The models developed in this paper focus only on live whorls. A multi-step model was developed from the bottom up, following procedures outlined by Pinheiro and Bates (2000) using model formulations and variables found to be important descriptors by other researchers (e.g., Maguire et al. 1991, 1994; Garber and Maguire 2005b; Weiskittel et al. 2007a; Kershaw et al. 2009). At each modelling step, traditional nonlinear regression estimation (nls), generalized nonlinear regression (gnls), and nonlinear mixed effects (nlme) procedures were used. The resulting models minimized random effects arising from the hierarchal nature of the data and produced biologically meaningful models.

\section{Maximum knot size}

For each live whorl, the largest knot was identified and labelled as the maximum whorl knot (MaxKnot). Whorl depth (WLDEPTH) was defined as distance from tree tip to top of each whorl (WLDEPTH = TOTHT - WLU). WLDEPTH varies within individual trees and is considered a within tree independent variable. For the other set of independent variables, only 1 value per tree was available; therefore, only between-tree variation exists and these variables are considered between-tree variables. The between-tree variables included diameter at breast height $(\mathbf{D B H})$, total tree height (TOTHT), height to crown base (HTCB), crown length (CRLEN), crown width (CRWIDTH), and spacing (SPACE).

The initial model only contained WLDEPTH, a withintree variable, and was fitted globally to the entire data and to each individual tree separately using the nlsList function in R. Visual examination of the distribution of parameter estimates and residuals between individual trees were used to determine if random effects were present and to determine which variables could be used to further reduce residual sums of squares. Within-tree autocorrelation was accounted for by using a continuous first-order autocorrelation function (CAR1).Weighting based on a power variance function of WLDEPTH was used to stabilize residual variances. The same autocorrelation function and weighting function were used for both gnls and nlme fits. All nls fits were unweighted. Significance of correlation and weighting were tested using likelihood ratio tests.

\section{Relative knot size}

Within each annual whorl, relative knot size was calculated by dividing knot size by maximum knot size (RelKS = KNOTD/MaxKnot). General linear models with a logit link and generalized nonlinear least squares using a negative exponential function were used to predict RelKS. Models based on relative whorl position $($ RelWhPos $=($ KNOTHT WLBOT)/(WLTOP - WLBOT) and knot rank based on height within whorl (highest $=1$ and lowest $=n$ ) were developed and compared.

Using the same approach described above for predicting MaxKnot, models were built from the bottom up. Goodness of fit statistics and residual patterns were explored at each step in the model-building process. The final model form was selected based on significance of individual parameter estimates, goodness of fit statistics, and the resulting residual patterns. Within tree autocorrelation was accounted for by using a continuous first-order autocorrelation function (CAR1) and effects due to the hierarchal nature of the data (nesting of knots within whorls within trees) were explored using nonlinear mixed effects models.

\section{Knot number}

Knot number per whorl was fitted using a Poisson distribution in a general linear mixed model with partial quasilikelihoods (Schall 1991, Wolfinger and O'Connell 1993). Again, models were built from the bottom up using plots of residuals to inform model development. Within-tree autocorrelation was again accounted for by using a continuous first-order autocorrelation function (CAR1), and weighting based on a power variance function of WLDEPTH was used to stabilize residual variances.

\section{Results}

The final model form for maximum live whorl knot size was:

\section{[1] MaxKnot $-\beta_{0}\left(\right.$ WLDEPTH $^{\beta_{1}}\left(\right.$ DBH $\left.^{\beta_{2}}\right)\left(\right.$ HTCB $\left.^{\beta_{3}}\right)$}

Parameter estimates and associated standard errors are summarized in Table 2 . The model accounted for $74 \%$ of the total variation and had a root MSE of 2.03. The resulting autocorrelation coefficient was 0.0011 and was significant $(\mathrm{p}=$ .0013). In the nonlinear mixed effects model, significant ( $\mathrm{p}=$ .024) random effects associated with $\beta_{0}$ and $\beta_{1}$ were found. The associated standard errors were $\mathrm{s}\left(\mathrm{b}_{0}\right)=.0297$ and $\mathrm{s}\left(\mathrm{b}_{1}\right)=$ .000912 . The random effects terms accounted for an additional $3 \%$ of the total variation. The equation showed a monotonic increase in maximum knot size with whorl depth and minimal curvilinearity near the crown base (Fig. 1).

The final model form for relative knot size was:

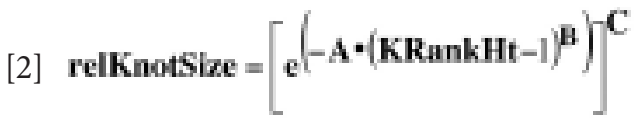

$$
\begin{aligned}
& \text { where } \\
& \mathbf{A}=\alpha_{0}+\alpha_{1} \text { WLDEPTH }^{\left(1+\alpha_{2} \text { DBH }\right)}+\alpha_{3} \text { TOTHT } \\
& \mathbf{B}-\beta_{0} \\
& \mathbf{C}=1+\chi_{1} \text { WLDEPTH }+\chi_{2} \text { WLLEN }
\end{aligned}
$$

Using Knot rank (KRankHt) minus one insured that relKnotSize $=1.0$ for the highest knot in each whorl which we assumed to be the maximum whorl knot. While this assumption was not always true, it provided the best compromise between goodness of fit and model function. A better fit was possible by placing a scalar parameter in front of the expo- 
Table 2. Regression statistics (including continuous first-order autocorrelation function [CAR]), parameter estimates and approximate standard errors (in parentheses) for maximum knot size, relative knot size and knot frequency models

\begin{tabular}{|c|c|c|c|c|}
\hline Model & $\mathbf{R}^{2}$ & RMSE & CAR & Equation \\
\hline MaxKnot & 0.74 & 2.03 & 0.0011 & 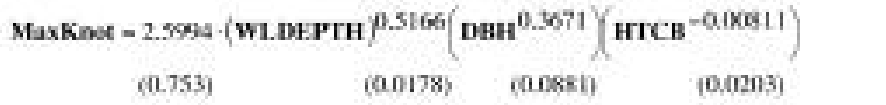 \\
\hline relKnotSize & 0.32 & 0.20 & NA & 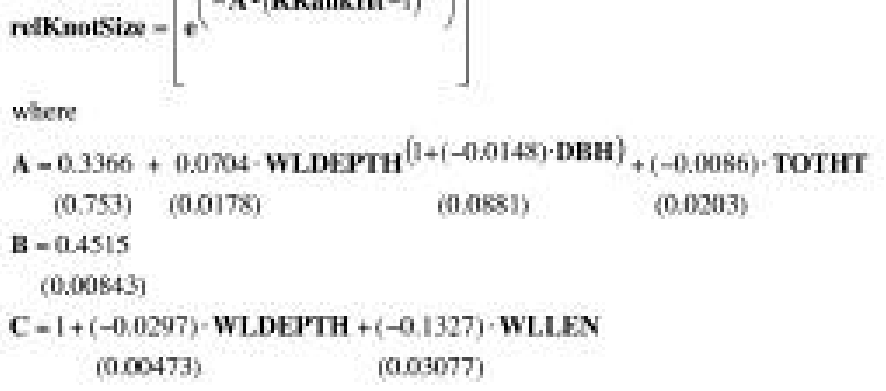 \\
\hline KFQ & 0.45 & 2.11 & 0.00 & 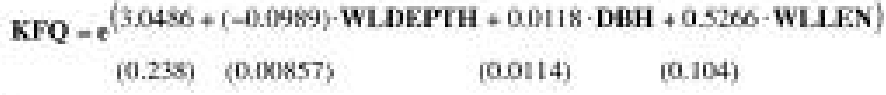 \\
\hline
\end{tabular}
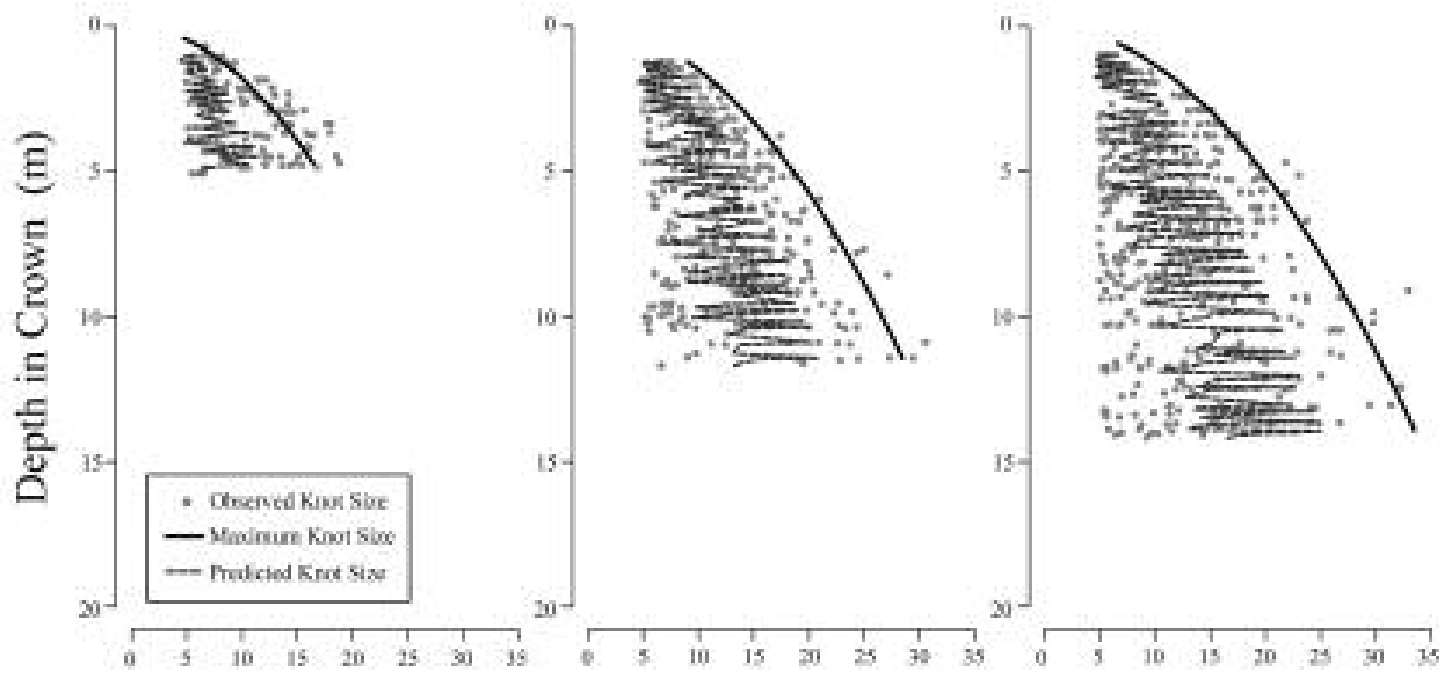

Knot Size (mm)

Fig. 1. Comparison of predicted knot size (maximum and within-whorl) using the median tree from each initial spacing, SP: (A) SP = 1.8 $\mathrm{m}, \mathrm{DBH}=18.0 \mathrm{~cm}$; (B) SP = $2.7 \mathrm{~m}, \mathrm{DBH}=23.0 \mathrm{~cm}$; and (C) $\mathrm{SP}=3.6 \mathrm{~m}, \mathrm{DBH}=26.5 \mathrm{~cm}$. The grey dots are observed knot size, while the black solid line is predicted maximum knot size and the dashed line is the predicted maximum knot size in each whorl.

nential (e); however, this resulted in maximum relKnotSize around .85 rather than 1.0 .

Parameter estimates and associated standard errors are summarized in Table 2 . The model only accounted for $32 \%$ of the total variation with a root MSE of .20, but was substantially better than any other model examined. The autocorre- lation coefficient was not significant $(\mathrm{p}=.36)$ and there were no significant random effects found. One possible explanation for the lack of significant random effects is the use of relative knot size rather than actual knot size. While potential for within-whorl autocorrelation exists, the between-whorl (within-tree) correlations would be eliminated. Relative knot 
$1.8 \mathrm{~m}$ Spacing
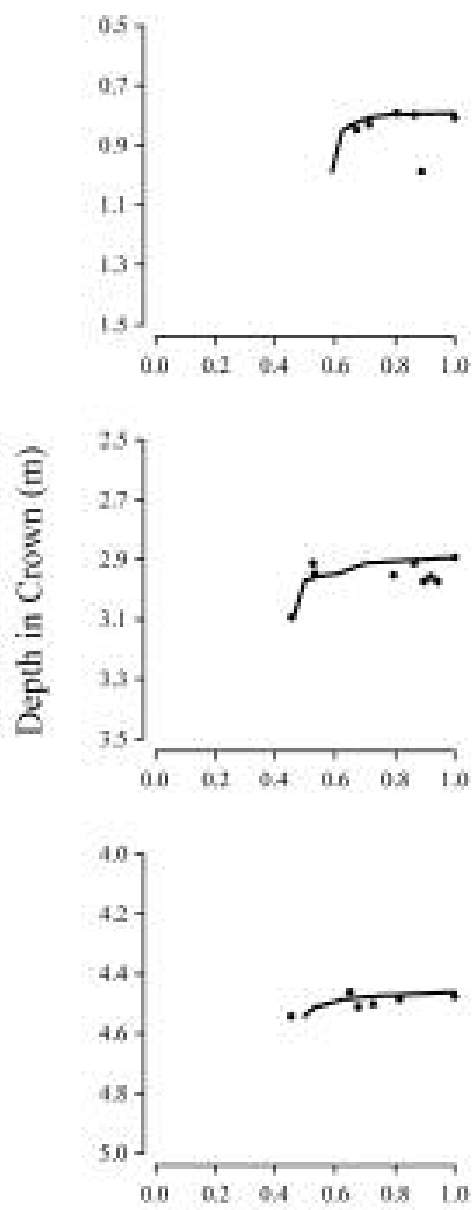

$2.7 \mathrm{~m}$ Spacing
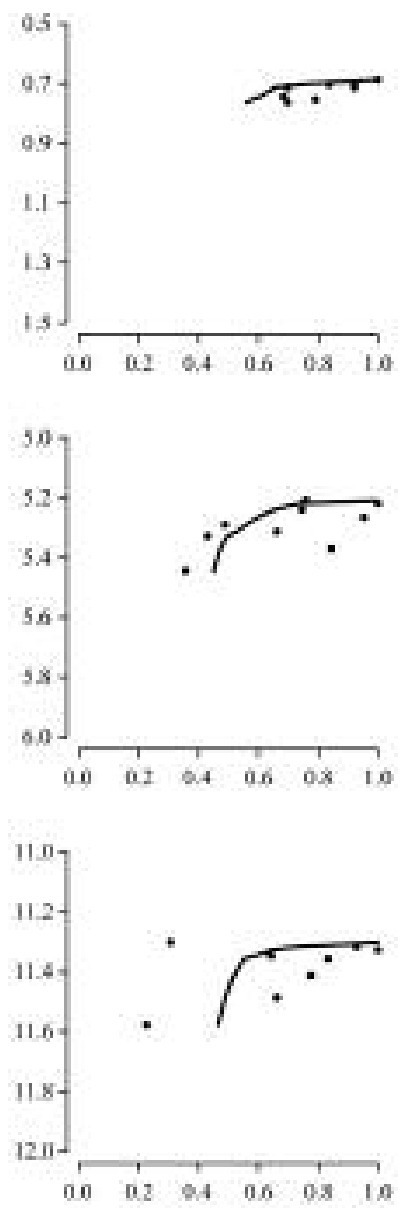

Relative Knot Size
$3.6 \mathrm{~m}$ Spacing
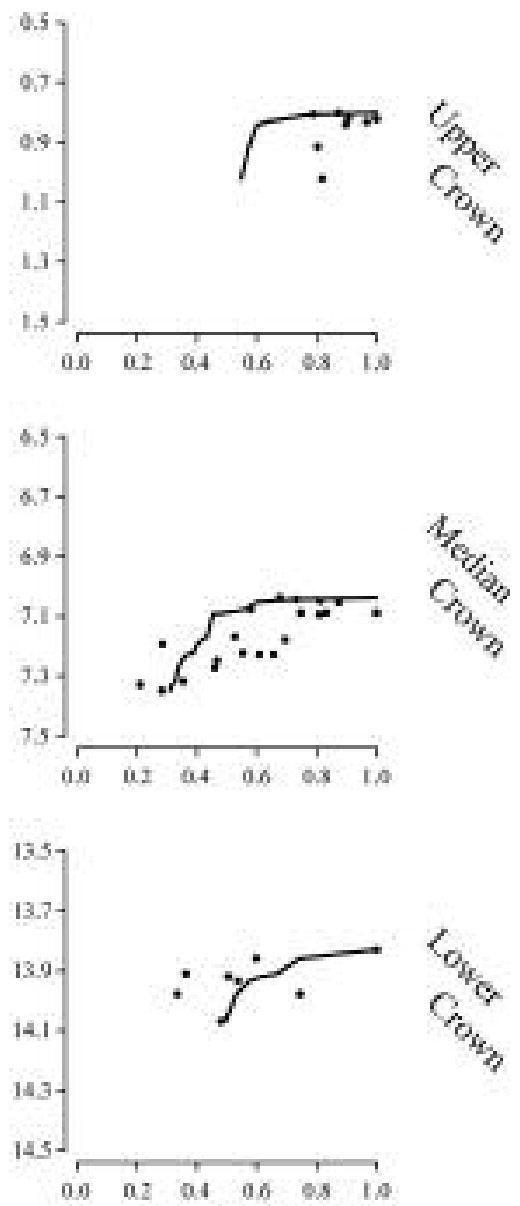

- Observation - Helative Koot Sice

Fig. 2. Comparison of predicted relative knot size at 3 crown locations using the median tree from each initial spacing, SP: (A) SP = 1.8 $\mathrm{m}, \mathrm{DBH}=18.0 \mathrm{~cm}$; (B) $\mathrm{SP}=2.7 \mathrm{~m}, \mathrm{DBH}=23.0 \mathrm{~cm}$; and (C) $\mathrm{SP}=3.6 \mathrm{~m}, \mathrm{DBH}=26.5 \mathrm{~cm}$. The black dots are observed relative knot size and the sold line is predicted relative knot size.

size decreases with increasing depth in crown (Fig. 2). Actual knot sizes within each whorl are predicted by multiplying MaxKnot by relKnotSize.

The final model form for knot number per whorl was:

\section{$[3] \mathrm{KFQ}=e^{\left(\beta_{0}+\beta_{1} \text { WLDEPTH }+\beta_{2} \mathrm{DBH}+\beta_{3} \text { WLLEN }\right)}$}

Parameter estimates and associated standard errors are summarized in Table 2. The model accounted for $45 \%$ of the total variation and the root MSE was 2.11. No significant autocorrelation or random effects were observed.

\section{Discussion and Conclusions}

This study developed, in part, from an opportunity to study influence of initial spacing on knot characteristics from the oldest OMNR black spruce spacing trial and it has produced one of the largest and most complete set of knot measurements in black spruce. Initial spacing, however, was dropped from all models because the parameter estimates were not significantly $(p>.05)$ different from 0 . Due to the small sample size (18 trees from 3 different spacings) and the problems with the Stanley Trial (flooding and lack of stand tending), these findings should not be surprising; although initially they appear contradictory to existing literature (Maguire et al. 1991, 1994; Oliver and Larson 1996). Kershaw et al. (2009) used an open-grown indicator in their models, which did improve goodness of fit, but accounted for very little additional variation. Effect of spacing in this study was most likely captured through other tree dimensions, particularly crown size (Table 1 and Fig. 1). As initial spacing increased, both 
crown length and crown width increased (Table 1). In terms of the knot models developed here, increase in crown dimensions was expressed by DBH and whorl depth in crown, WLDEPTH - as crown length increased, live branches were found deeper in the crown.

Initial spacing was found to indirectly influence knot number per whorl through increased DBH and tree height components (whorl length, WLLEN, and depth of whorl in crown, WLDEPTH). Decreasing knot number per whorl with increasing depth into crown is also consistent with the findings of Maguire et al. (1994). Although depth into crown was not specifically measured by Drolet et al. (1971) they did observe that number of branches per foot decreased when measured from merchantable height to the stump. Length of leader has been shown to influence number of lateral buds in spruces (Cannell and Bowler 1978). Given that lateral buds develop into branches, it is not surprising that branch number was related to leader length. Cochrane and Ford (1978) and Maguire et al. (1994) found that the number of branches per whorl was positively correlated with shoot length in Sitka spruce (Picea sitchensis [Bong.] Carr.) and Douglas-fir (Pseudotsuga menziesii [Mirb.] Franco), respectively. The same result was found in this study, but a considerable amount of variability was left unexplained by the knot frequency model. The reason for this may be related to lateral bud formation and branch size. Some lateral buds remain latent and do not develop into branches. A branch size limit was also established in the above studies prior to branch measurement and model development. Although this was necessary for the study of wood quality, the result is that an unknown number of branches were not considered in other modelling attempts.

\section{Management implications}

Knots (branches) are the most prominent wood quality feature visible on both standing trees and solid wood products. From a lumber processing perspective, the ability to predict or describe size and number of knots on a stem would greatly assist in log grading and sawing strategy decisions. It has been shown that consideration for knots during primary breakdown may improve lumber grade recovery (Wagner and Taylor 1975, Samson 1993, Lemieux et al. 2002, Benjamin et al. 2007). Therefore, any model that predicts the size and frequency of knots within a whorl will be useful to log sawing optimization and potential improvement of lumber grade yield and properties.

In terms of management implications, model results imply that any increase in knot size is the result of increased crown size and branch longevity. Similar to the approach developed by Maguire et al. (1991), models developed in this study could be used to design silviculture treatments that control crown dimensions and knot size. The obvious example would be initial tree spacing or stand density management through thinning treatments. The models can also be applied statically to output from growth and yield models provided the proper tree-level attributes are available. However, the models developed in this study explained a limited amount of the original variation so some caution in their application is warranted. For example, the knot models developed in this study need to be verified using trees from thinned stands, but any treatment that impacts crown recession will also influence knot size and is important for future wood quality considerations.

\section{Acknowledgements}

The authors would like to express their thanks to Mr. Colin Bowling and Mr. Bill Towill from the Ontario Ministry of Natural Resources for both materials and access to historical field measurements from the Stanley Spacing Trial. Funding for this research was provided by the NSERC Strategic Project - Black Spruce Density Management and FPInnovations Forintek Division. This is paper 3059 of the Maine Agriculture and Forest Experiment Station.

\section{References}

Ballard, L.A. and L.N. Long. 1988. Influence of stand density on log quality of lodgepole pine. Can. J. For. Res. 18: 911-916.

Bendtsen, B.A. 1978. Properties of wood from improved and intensively managed trees. For. Prod. J. 28: 61-72.

Benjamin, J. 2006. Assessing lumber grade recovery improvement potential of black spruce (Picea mariana (Mill.) B.S.P.) by modelling knot characteristics. PhD dissertation. The University of New Brunswick, Fredericton, NB. 186 p.

Benjamin, J., Y.H. Chui and S.Y. Zhang. 2007. A method to assess lumber grade recovery improvement potential for black spruce logs based on branchiness. For. Prod. J. 57: 34-41.

Björklund, L. and H. Petersson. 1999. Predicting knot diameter of Pinus sylvestris in Sweden. Scand. J. For. Res. 14: 376-384.

Cannell, M.G.R. and K.C. Bowler. 1978. Spatial arrangement of lateral buds at the time that they form on leaders of Picea and Larix. Can. J. For. Res. 8: 129-137.

Caron, G.E. 1987. Development of branch patterns and seed production in young black spruce (Picea mariana (Mill.) B.S.P.). Ph.D. dissertation, University of New Brunswick, Fredericton, NB. 300 p. Cochrane, L.A. and E.D. Ford. 1978. Growth of a Sitka spruce plantation: Analysis and stochastic description of the development of the branching structure. J. Appl. Ecol. 15: 227-244.

Colin, F. and F. Houllier. 1991. Branchiness of Norway spruce in north-eastern France: modelling vertical trends in maximum nodal branch size. Ann. Sci. For. 48: 679-693.

Doruska, P.F. and H.E. Burkhart. 1994. Modeling the diameter and locational distribution of branches within the crowns of loblolly pine trees in unthinned plantations. Can. J. For. Res. 24: 2362-2376.

Drolet, J.-C., R.M. Newnham and T.B. Tsay. 1971. Branchiness of Jack Pine, Black Spruce and Balsam Fir in Relation to Mechanized Delimbing. Can. Dep. Environ., Can. For. Serv., For. Manage. Inst. Inf. Rep. FMR-X-34. 34 p.

Eversole, K.R. 1955. Spacing Tests in a Douglas-Fir Plantation. For. Sci. 1: 14-18.

Fujimori, T. 1993. Dynamics of crown structure and stem growth based on knot analysis of a hinoki cypress. For. Ecol. Manag. 56: 57-68.

Garber, S.M. and D.A. Maguire. 2005a. The response of vertical foliage distribution to spacing and species composition in mixed conifer stands in central Oregon. For. Ecol. Manag. 211: 341-355.

Garber, S.M. and D.A. Maguire. 2005b. Vertical trends in maximum branch diameter in two mixed-species spacing trials in the central Oregon Cascades. Can. J. For. Res. 35: 295-307.

Gillespie, A.R., H.L. Allen and J.M. Vose. 1994. Amount and vertical distribution of foliage of young loblolly pine trees as affected by canopy position and silvicultural treatment. Can. J. For. Res. 24: 1337-1344.

Grah, R.F. 1961. Relationship between tree spacing, knot size, and $\log$ quality in young Douglas-Fir stands. J. For. 59: 270-272.

Haygreen, J.G. and J.L. Bowyer. 1996. Forest Products and Wood Science: An Introduction. Third ed. Iowa State University Press.

Kerrio, V.G. 1989. Forest Research and Management Demonstration Area: Thunder Bay Spacing Trial. Queen's Printer. 5 p.

Kershaw, J.A., J.G. Benjamin and A.R. Weiskittel. 2009. Modeling Vertical Maximum Knot Distribution Using Nonlinear Mixed Effects Models: A Modeling Approach. For. Sci. 55: 230-237. 
Kershaw, J.A. and D.A. Maguire. 1996. Crown structure in western hemlock, Douglas-fir, and grand fir in western Washington: horizontal distribution of foliage within branches. Can. J. For. Res. 26: 128-142.

Kershaw, J.A., D.A. Maguire and D.W. Hann. 1990. Longevity and duration of radial growth in Douglas-fir branches. Can. J. For. Res. 20: $1690-1695$.

Lejeune, G. 2004. Prédiction du défilement et de la branchaison de lépinette noire. Unpubl. M.Sc.F., Université Laval - Faculté de Foresterie et de Géomatique. $41 \mathrm{p}$.

Lemieux, L., M. Beaudoin and S.Y. Zhang. 2001. Characterization and modeling of knots in black spruce logs. Wood and Fiber Sci. 33(3): 465-475.

Lemieux, H., S.Y. Zhang and F. Grondin. 2002. Improving Structural Lumber Quality in a Sample of Picea mariana Logs Sawn According to the Knots. Wood and Fiber. Sci. 34: 266-275.

MacDonald, E. and J. Hubert. 2002. A review of the effects of silviculture on timber quality of Sitka spruce. Forestry 75: 107-138.

Maguire, D.A. and W.S. Bennett. 1996. Patterns in vertical distribution of foliage in young coastal Douglas-fir. Can. J. For. Res. 26: 1991-2005.

Maguire, D.A., S.R. Johnston and J. Cahill. 1999. Predicting branch diameters on second-growth Douglas-fir from tree-level descriptors. Can. J. For. Res. 29: 1829-1840.

Maguire, D.A., J.A. Kershaw and D.W. Hann. 1991. Predicting the effects of silvicultural regime on branch size and crown wood core in Douglas-fir. For. Sci. 37: 1409-1428.

Maguire, D.A., M. Moeur and W.S. Bennett. 1994. Models describing basal diameter and vertical distribution of primary branches in young Douglas-fir. For. Ecol. Manag. 63: 23-55.

Mäkinen, H. and A. Mäkelä. 2003. Predicting basal area of Scots pine branches. For. Ecol. Manag. 179: 351-362.

Moberg, L. 2000. Models of internal knot diameter for Pinus sylvestris. Scand. J. For. Res. 15: 177-187.
Moberg, L. 2001. Models of internal knot properties for Picea abies. For. Ecol. Manag. 147: 123-138.

Oliver, C.D. and B.C. Larson. 1996. Forest Stand Dynamics. Updated ed. John Wiley and Sons Inc.

Pinheiro, J.C. and D.M. D.M. 2000. Mixed-effects models in S and S-Plus. Springer-Verlag, New York.

R Development Core Team. 2008. R: A language and environment for statistical computing. R Foundation for Statistical Computing. Vienna, Austria.

Samson, M. 1993. Method for assessing the effect of knots in the conversion of logs into structural lumber. Wood and Fiber Sci. 25: 298-304.

Schall, R. 1991. Estimation in generalized linear models with random effects. Biometrika 78: 719-727.

Wagner, F.G. and F.W. Taylor. 1975. Simulated sawing with a chipping headrig. For. Prod. J. 25: 24-28.

Weiskittel, A.R., D.A. Maguire and R.A. Monserud. 2007a. Modeling crown structural responses to competing vegetation control, thinning, fertilization, and Swiss needle cast in coastal Douglas-fir of the Pacific Northwest, USA. For. Ecol. Manag. 245: 96-109.

Weiskittel, A.R., D.A. Maguire and R.A. Monserud. 2007b. Modeling individual branch growth and mortality in intensively managed Douglas-fir plantations: Implications for predicting individual tree growth. For. Ecol. Manag. 251:182-194.

Wolfinger, R. and M. O’Connell. 1993. Generalized linear mixed models: a pseudo-likelihood approach. J. Stat. Comput. Sim. 48: 233-243.

Zhang, S.Y., G. Chauret, H.Q. Ren and R. Desjardins. 2002. Impact of initial spacing on plantation black spruce lumber grade yield, bending properties and MSR yield. Wood and Fiber Sci. 34: $460-475$. 